\section{Why do patients still require surgery for the late complications of Proliferative Diabetic Retinopathy?}

PH Scanlon

\begin{abstract}
Aim To briefly review and discuss the literature on why patients still require surgery for the late complications of proliferative diabetic retinopathy (PDR).

Methods: Literature review.

Results The reasons for incomplete coverage of screening and screening failures can be divided into non-modifiable and potentially modifiable risk factors. The non-modifiable group includes duration of diabetes, age, genetic predisposition, ethnic differences, and the various reasons for vitrectomy when optimum laser treatment has been applied at the appropriate stage of the disease process. The potentially modifiable group includes glycaemic control, blood pressure control, lipid control, and cessation of smoking in type 1 diabetes. Other potentially modifiable factors include adequacy of screening, including reaching the regular non-attender, and attempting to modify the psychological factors that lead to late presentations including depression and eating disorders. Other potentially modifiable risk factors are optimising laser treatments and the potential use of anti-VEGF therapy to prevent vitrectomy in iris neovascularisation and neovascular glaucoma.

Conclusion Surgery for the late complications of PDR continues to be required even in some patients who have received optimal medical care and optimal laser treatment. There are certain modifiable risk factors that could be altered and further research is needed in specific fields, particularly with regard to the adequacy of laser treatments, the use of anti-VEGF agents
\end{abstract}

in iris neovascularisation, and in the role of psychological support in reducing the type of late complications leading to surgery for PDR. Eye (2010) 24, 435-440; doi:10.1038/eye.2009.320; published online 8 January 2010

Keywords: vitrectomy; screening; diabetic retinopathy; neovascular glaucoma

\section{Introduction}

It was apparent at the Liverpool Conference ${ }^{1}$ on 'Screening for Diabetic Retinopathy in Europe' in 2005 that some countries (eg, Uzbekistan) had no available lasers at that time for their population. However, I have made the assumption in this article that the patient group that we are discussing has access to both laser treatment and surgery for the late complications of proliferative diabetic retinopathy (PDR).

In this review, my aim was to identify modifiable and non-modifiable risk factors relating to late complications of diabetic retinopathy and to discuss potential ways in which one might reduce the modifiable risk factors.

I have defined surgery for late complications of diabetic retinopathy as

1. vitrectomy for those complications of diabetic retinopathy that are widely accepted as requiring this form of treatment;

2. surgical treatment for rubeosis iridis with or without secondary glaucoma, due to diabetic retinopathy.

I have excluded scatter or panretinal laser treatment from the definition of surgery for late
Gloucestershire Eye Unit, Cheltenham General Hospital, Cheltenham, UK

Correspondence: PH Scanlon, Consultant Ophthalmologist, Gloucestershire Eye Unit, Cheltenham General Hospital, Sandford Rd, Cheltenham GL53 7AN, UK Tel: 448454 224468; Fax: 448454224420. E-mail: peter.scanlon@ glos.nhs.uk

Received: 2 September 2009

Accepted in revised form: 17 November 2009 Published online: 8 January 2010

This work will be presented at the Cambridge Ophthalmological Symposium 
complications of diabetic retinopathy, as this is the recognised treatment for high-risk proliferative diabetic retinopathy.

\section{Methods}

The methodology of the literature review was as follows:

1. The author's ongoing literature review (since March 2000) involves a search technique using Zetoc, which is a co-operative venture between the British Library, Manchester Information and Associated Services (MIMAS), and the Joint Information Systems Committee of the UK Higher Education Funding Council (http://zetoc.mimas.ac.uk). Zetoc provides access to the British Library's Electronic Table of Contents of around 20000 of the most important research journals worldwide and around 16000 conference proceedings published per year. The database covers articles from 1877 to date and is updated on a daily basis. The following subject title keywords have been set up for this ongoing review-Blindness, Retinopathy, Diabetic retinopathy, Screening, Digital imaging, Visual acuity, Laser, Visual impairment, and Vitrectomy. A total of 32 journals are also selected for contents page lists. There are 3422 abstracts in the database. Searching this database for the title word of vitrectomy resulted in 143 abstracts, detachment yielded 43 abstracts, neovascular glaucoma yielded 9 abstracts, and blindness gave 76 abstracts. All of these articles were available from the review files.

2. A PUBMED search (from January 1986 to May 2009) was undertaken specifically for this topic including additional areas not in the author's on going literature review, such as the psychological aspects of diabetic retinopathy-68 articles were identified using this technique.

3. A total of 16 additional references were selected from the bibliographies of identified articles.

4. The instructions for this article were to include only 50 references.

\section{Results}

In this literature review, I found high-quality recent reviews of the indications for vitrectomy by $\mathrm{Helbig}^{2}$ and Joussen $^{3}$ and evidence of improving visual results during the last 20 years following vitrectomy in articles by Blankenship, ${ }^{4}$ Thompson, ${ }^{5}$ and more recently by Lahey $^{6}$ and Yorston. ${ }^{7}$

This review identified the following risk factors for late complications of diabetic retinopathy requiring surgery that were not modifiable:
1. Duration of diabetes - there is a clear link between duration and progression of diabetic retinopathy. ${ }^{8,9}$

2. Age-there is a rather complex link with age in the Wisconsin Epidemiological Study ${ }^{10-12}$ showing that in those whose age of diagnosis was less than 30 years and who had diabetes of 10 years duration or less, the severity of retinopathy was related to older age at examination, whereas when the age at diagnosis was 30 or more years, the severity of retinopathy was related to younger age at diagnosis. In the UKPDS, ${ }^{13}$ in those who already had retinopathy, progression was associated with older age.

3. Genetic predisposition ${ }^{14}$-in a study on 4800 adults with type I diabetes in Finland, a familial clustering of proliferative retinopathy was found in patients with type I diabetes, which could not be accounted for by conventional risk factors, suggesting a genetic component in the pathogenesis of proliferative retinopathy in type I diabetes

4. Ethnic differences - two studies, ${ }^{15,16}$ one comparing Hispanics, African Americans, and non-Hispanic whites and the other comparing European, Maori, and Pacific people, suggested that ethnic differences could not be explained by an imbalance in traditional risk factors such as age, duration of diagnosed diabetes, $\mathrm{HbA1c}$, and blood pressure.

5. The requirement for vitrectomy despite optimum laser treatment being applied at the appropriate stage of disease progression.

Of the eyes that were treated at the stage of high-risk proliferative diabetic retinopathy under the Early Treatment Diabetic Retinopathy Study research conditions, $4 \%$ required vitrectomy ${ }^{17}$ within 5 years and $2.1 \%$ of eyes treated with early full scatter photocoagulation still needed vitrectomy. Although this study is 15 years old, it showed that optimum laser does not always prevent a vitrectomy operation. It may be that there are other modifiable factors that could have reduced the risk of vitrectomy in this small percentage of patients but optimum laser treatment alone did not. The following are reasons why vitrectomy may be required despite optimum laser treatment:

(a) Non-clearing vitreous haemorrhage-following the results of the diabetic vitrectomy study, ${ }^{18,19}$ vitrectomy is usually considered early (after approximately 1 month) for a severe vitreous haemorrhage with no signs of spontaneous clearing in a patient with type I diabetes, and the haemorrhage is usually given a longer time to clear spontaneously in type II diabetes or if panretinal photocoagulation has previously been applied.

(b) A large subhyaloid macular haemorrhage. 
(c) Tractional retinal detachment - vitrectomy is usually advised for situations in which the macula is involved or clearly threatened ${ }^{20}$ by progressive tractional detachment.

(d) Combined rhegmatogenous/tractional retinal detachment - the rhegmatogenous component is induced by progressive fibrovascular contraction and early surgical results were reported by Thompson. ${ }^{21}$

(e) Progressive severe fibrovascular proliferation - this may occur despite adequate panretinal photocoagulation and early vitrectomy in this group of patients is advocated by Favard. ${ }^{22}$

(f) Taut posterior hyaloid in diabetic macular oedema - a review by Laidlaw ${ }^{23}$ on vitrectomy for diabetic macular oedema concluded that the evidence at present suggests that vitrectomy for Diabetic Macular Oedema should be restricted to those with clinical or OCT signs of traction.

The following potentially modifiable factors have been well documented in the literature:

1. Glycaemic control-evidence for the link between poor glucose control and greater progression of diabetic retinopathy (DR) has been provided by numerous studies. ${ }^{24,25}$

2. Blood pressure control-control of systemic hypertension has been shown to reduce the risk of new onset DR and slow the progression of existing DR. ${ }^{26,27}$

The following are also potentially modifiable risk factors:

3. Lipid control-there is evidence ${ }^{28,29}$ that elevated serum lipids are associated with macular exudates and moderate visual loss and partial regression of hard exudates may be possible by reducing elevated lipid levels.

4. Smoking is considered to be a risk factor for type 1 disease, ${ }^{30}$ although the evidence for smoking being a risk factor in type 2 disease is controversial with the UKPDS data, ${ }^{13}$ suggesting that smoking may have a protective effect on retinopathy, even though it is a major risk factor for mortality.

5. Incomplete coverage of screening.

Posters at the Liverpool Conference ${ }^{1}$ in 2005 showed that there were large variations in screening activity in Europe, with annual national diabetic retinopathy screening programmes in England, Scotland, Wales, Northern Ireland, and Iceland, whereas in Denmark, regional programmes have developed and, in many other European countries, for example Eire, France, Germany, Greece, Israel, Italy, Luxembourg, Netherlands, Portugal, and Spain, local screening programmes have developed upon the initiative of individual persons, and coverage across the country is variable. In Eastern

Europe, the provision of screening was very variable. In the United States, provision of screening is mostly for those who can pay, and it is estimated ${ }^{31}$ that there are more than 47 million Americans who have no health-care insurance.

Even in countries in which comprehensive screening programmes exist and there are no economic considerations for attendance for a person with diabetes, there are variations in uptake. Zoega ${ }^{32}$ showed a significant relationship between screening compliance and visual outcome in patients with diabetes in the Icelandic screening programme. Diabetic patients (type I and type II) listed in the National Register for the blind had significantly lower rates of screening compliance $(27+38 \%$ than those in the control group $(77+26 \%)$. In the treatment phase, once diabetic macular oedema or proliferative diabetic retinopathy was diagnosed, there was no significant difference $(83+27$ versus $87+12 \%)$. Gray $^{33}$ has shown a link between the number of reminders required for attendance in the screening programme in Somerset, United Kingdom and the grade of retinopathy identified. In a study ${ }^{34}$ in Gloucestershire, United Kingdom, sight-threatening diabetic retinopathy was found to be present most frequently in the most deprived socio-economic group, and this group was the least likely to attend screening.

\section{Psychological aspects causing late presentation}

As vitrectomy operations are performed for more advanced stage disease, it follows that patients who present late with advanced disease are more likely to require a vitrectomy. Gale ${ }^{35}$ wrote in his review article on 'How to survive diabetes' that the likely major determinants of long-term survival are 'metabolic control, destiny and character'. He also wrote that it was 'sad to relate, we have made little progress in understanding the human determinants of long-term survival with diabetes, and the social, behavioural and psychological basis of long-term diabetes has not been studied, despite the central role of self-management in achieving this outcome'.

Szydlo ${ }^{36}$ found that the diagnosis of DM is a significant stress factor not only for patients but also for their environment. Children with DM are sometimes stigmatised by their peers and relatives who do not understand the illness or are frightened by it. The family's response to the diagnosis of DM may have a negative effect on glycaemic control. Rose $^{37}$ studied the multitude of somatic and psychological factors in achieving treatment goals and found that belief in self-efficacy and active coping behaviour influenced 
maintaining blood glucose levels close to normal. Weinger ${ }^{38}$ recommended that interventions designed to help patients overcome attitudinal barriers should be incorporated into medical programmes geared towards improving glycaemia. Gale ${ }^{35}$ suggested that anyone who came into contact with long-term survivors of diabetes will probably agree that these are self-directed people with a lot more than diabetes to live for.

Patients with diabetes have an increased risk of depressive symptoms, which may have an additional negative effect on their quality of life. A recent systematic review by Schram $^{39}$ summarised the current knowledge on the association between depressive symptoms and quality of life in individuals with diabetes. The review concluded that in addition to the considerable effect of depression on quality of life in individuals with diabetes, depression also contributes to poor self-care, poor adherence to medical treatment, higher rates of medical morbidity and mortality, and increased health-care costs.

One area that I have been aware that causes significant problems in my own patients with respect to late presentations and the need for surgery for the late complications of PDR is eating disorders in both type I and type $\mathrm{II}^{40}$ diabetes. This has been studied by GoebelFabri ${ }^{41,42}$ in patients with type I diabetes and can cause particular problems with metabolic control and progression to very severe diabetic retinopathy in young women. Insulin omission and reduction and eating disorder symptoms unique to diabetes mellitus are strongly associated with an increased risk of severe microvascular complications of diabetes mellitus such as advanced proliferative DR requiring vitrectomy.

\section{Adequacy of laser treatment}

There is an optimum amount of laser treatment for each individual patient. The Diabetic Retinopathy Study (DRS) recommended that the amount of retina treated is equivalent to an area of $157-314 \mathrm{~mm}^{2}$, whereas the ETDRS recommended an area equivalent from $236 \mathrm{~mm}^{2}$ to $314 \mathrm{~mm}^{2}$. Reddy ${ }^{43}$ showed that the amount of initial treatment required for regression may be considerably more than that recommended by the Diabetic Retinopathy Study and that more extensive treatment was required with more retinopathy risk factors.

In 1998, Bailey ${ }^{44,45}$ reported the results of the UK National Diabetic Retinopathy Laser Treatment Audit, which showed that many UK Ophthalmologists were undertreating compared with the DRS or ETDRS protocols. For the subgroup with the equivalent of highrisk characteristics who were given their initial treatment in one session $(n=65)$, the median retinal area treated was $104.6 \mathrm{~mm}^{2}$ (range $10.4 \mathrm{~mm}^{2}-682.5 \mathrm{~mm}^{2}$ ) or $377.6 \mathrm{~mm}^{2}$ (range $37.6 \mathrm{~mm}^{2}-2464 \mathrm{~mm}^{2}$ ) if the quadraspheric had been used for all cases.

8. The potential use of anti-VEGF therapy to prevent vitrectomy in neovascular glaucoma.

Iris neovascularisation and glaucoma secondary to diabetic retinopathy are believed to be caused by the vasoproliferative growth factors produced by an ischaemic retina. ${ }^{46}$ The aim of treatment is therefore to treat the ischaemic retina with panretinal photocoagulation but applying panretinal photocoagulation can be made more difficult because of corneal oedema produced as a consequence of raised intraocular pressure. Some patients require a vitrectomy, ${ }^{47}$ but the visual prognosis depends on how early the iris neovascularisation and elevated intraocular pressure are detected and treated. Others require transscleral diode laser cyclophotocoagulation, ${ }^{48}$ but there is a risk of hypotony and phthisis in diabetic neovascular glaucoma in eyes that have had multiple pars plana vitrectomies. There are some recent reports ${ }^{49,50}$ of shortterm regression of iris neovascularisation after intravitreal injection of bevacizumab in patients with proliferative diabetic retinopathy. Jiang ${ }^{50}$ conducted a retrospective analysis of 28 eyes of 22 patients. Significant regression of iris neovascularisation was noted in 20 eyes (71.4\%). Further studies are needed to evaluate long-term results but this may offer some patients a time period during which panretinal photocoagulation can be applied without needing to resort to vitrectomy or transscleral diode laser cyclophotocoagulation.

\section{Discussion}

This review has shown that there are numerous nonmodifiable and modifiable risk factors for surgery for the late complications of PDR. In different health-care environments, the question arises as to whether we could be doing anything more about the modifiable risk factors.

There is rightly a considerable emphasis among physicians and primary care practitioners on control of glycaemia, blood pressure, and lipids. Screening programmes vary in different countries but efforts need to be made to screen the regular non-attenders, as these are the patients most at risk. I believe that more studies should be carried out following the results of the Royal College of Ophthalmology audit to improve training in laser treatment in the United Kingdom and to re-audit the results that were presented in 1999; there is no current evidence that laser treatments have improved since that time. Further work is required to understand the current levels of laser coverage for patients being referred for vitrectomy and what one might consider to 
be the optimum level of laser treatment, given that the vitrectomy complication rates continue to reduce.

The early results of the use of anti-VEGF agents in iris neovascularisation are encouraging but further research is needed in this field to inform the optimum timing and dose of this treatment.

Further work also needs to be carried out into the social, behavioural, and psychological basis of long-term diabetes and into the role of psychological support in reducing the type of complications leading to surgery for PDR.

\section{Conflict of interest}

The author declares no conflict of interest.

\section{References}

1 The Liverpool Declaration 2005, Report of Conference. Screening for Diabetic Retinopathy in Europe 15 years after the St Vincent Declaration; 2005 17th-18th November 2005; Liverpool http://www.drscreening2005.org.uk/ conference_report.doc.

2 Helbig H. Surgery for diabetic retinopathy. Ophthalmologica 2007; 221(2): 103-111.

3 Joussen AM, Joeres S. Benefits and limitations in vitreoretinal surgery for proliferative diabetic retinopathy and macular edema. Dev Ophthalmol 2007; 39: 69-87.

4 Blankenship GW, Machemer R. Long-term diabetic vitrectomy results. Report of 10 year follow-up. Ophthalmology 1985; 92(4): 503-506.

5 Thompson JT, de Bustros S, Michels RG, Rice TA, Glaser BM. Results of vitrectomy for proliferative diabetic retinopathy. Ophthalmology 1986; 93(12): 1571-1574.

6 Lahey JM, Francis RR, Kearney JJ. Combining phacoemulsification with pars plana vitrectomy in patients with proliferative diabetic retinopathy: a series of 223 cases. Ophthalmology 2003; 110(7): 1335-1339.

7 Yorston D, Wickham L, Benson S, Bunce C, Sheard R, Charteris D. Predictive clinical features and outcomes of vitrectomy for proliferative diabetic retinopathy. $\mathrm{Br} J$ Ophthalmol 2008; 92(3): 365-368.

8 Klein R, Klein BE, Moss SE, Davis MD, DeMets DL. The Wisconsin Epidemiologic Study of Diabetic Retinopathy. IX. Four-year incidence and progression of diabetic retinopathy when age at diagnosis is less than 30 years. Arch Ophthalmol 1989; 107(2): 237-243.

9 Klein R, Klein BE, Moss SE, Davis MD, DeMets DL. The Wisconsin Epidemiologic Study of Diabetic Retinopathy. X. Four-year incidence and progression of diabetic retinopathy when age at diagnosis is 30 years or more. Arch Ophthalmol 1989; 107(2): 244-249.

10 Klein R, Klein BE, Moss SE, Davis MD, DeMets DL. The Wisconsin epidemiologic study of diabetic retinopathy. II. Prevalence and risk of diabetic retinopathy when age at diagnosis is less than 30 years. Arch Ophthalmol 1984; 102(4): 520-526.

11 Klein R, Klein BE, Moss SE, Davis MD, DeMets DL. The Wisconsin epidemiologic study of diabetic retinopathy. III. Prevalence and risk of diabetic retinopathy when age at diagnosis is 30 or more years. Arch Ophthalmol 1984; 102(4): 527-532.

12 Klein R, Klein BE, Moss SE, Cruickshanks KJ. The Wisconsin Epidemiologic Study of diabetic retinopathy. XIV. Ten-year incidence and progression of diabetic retinopathy. Arch Ophthalmol 1994; 112(9): 1217-1228.

13 Stratton IM, Kohner EM, Aldington SJ, Turner RC, Holman RR, Manley SE et al. UKPDS 50: risk factors for incidence and progression of retinopathy in Type II diabetes over 6 years from diagnosis. Diabetologia 2001; 44(2): 156-163.

14 Hietala K, Forsblom C, Summanen P, Groop PH. Heritability of proliferative diabetic retinopathy. Diabetes 2008; 57(8): 2176-2180.

15 Emanuele N, Sacks J, Klein R, Reda D, Anderson R, Duckworth $\mathrm{W}$ et al. Ethnicity, race, and baseline retinopathy correlates in the veterans affairs diabetes trial. Diabetes Care 2005; 28(8): 1954-1958.

16 Simmons D, Clover G, Hope C. Ethnic differences in diabetic retinopathy. Diabet Med 2007; 24(10): 1093-1098.

17 Flynn Jr HW, Chew EY, Simons BD, Barton FB, Remaley NA, Ferris III FL. Pars plana vitrectomy in the Early Treatment Diabetic Retinopathy Study. ETDRS report number 17. The Early Treatment Diabetic Retinopathy Study Research Group. Ophthalmology 1992; 99(9): 1351-1357.

18 Early vitrectomy for severe vitreous hemorrhage in diabetic retinopathy. Two-year results of a randomized trial. Diabetic Retinopathy Vitrectomy Study report 2. The Diabetic Retinopathy Vitrectomy Study Research Group. Arch Ophthalmol 1985; 103(11): 1644-1652.

19 Early vitrectomy for severe vitreous hemorrhage in diabetic retinopathy. Four-year results of a randomized trial: Diabetic Retinopathy Vitrectomy Study Report 5. Arch Ophthalmol 1990; 108(7): 958-964.

20 Meier P, Wiedemann P. Vitrectomy for traction macular detachment in diabetic retinopathy. Graefes Arch Clin Exp Ophthalmol 1997; 235(9): 569-574.

21 Thompson JT, de Bustros S, Michels RG, Rice TA. Results and prognostic factors in vitrectomy for diabetic tractionrhegmatogenous retinal detachment. Arch Ophthalmol 1987; 105(4): 503-507.

22 Favard C, Guyot-Argenton C, Assouline M, Marie-Lescure C, Pouliquen YJ. Full panretinal photocoagulation and early vitrectomy improve prognosis of florid diabetic retinopathy. Ophthalmology 1996; 103(4): 561-574.

23 Laidlaw DA. Vitrectomy for diabetic macular oedema. Eye 2008; 22(10): 1337-1341.

24 The effect of intensive treatment of diabetes on the development and progression of long-term complications in insulin-dependent diabetes mellitus. The diabetes control and complications trial research group. N Engl J Med 1993; 329(14): 977-986.

25 Intensive blood-glucose control with sulphonylureas or insulin compared with conventional treatment and risk of complications in patients with type 2 diabetes (UKPDS33). UK Prospective Diabetes Study (UKPDS) Group. Lancet 1998; 352(9131): 837-853.

26 Chase HP, Garg SK, Jackson WE, Thomas MA, Harris S, Marshall G et al. Blood pressure and retinopathy in type I diabetes. Ophthalmology 1990; 97(2): 155-159.

27 Matthews DR, Stratton IM, Aldington SJ, Holman RR, Kohner EM. Risks of progression of retinopathy and vision loss related to tight blood pressure control in type 2 diabetes mellitus: UKPDS 69. Arch Ophthalmol 2004; 122(11): 1631-1640. 
28 Chew EY, Klein ML, Ferris 3rd FL, Remaley NA, Murphy $\mathrm{RP}, \mathrm{Chantry} \mathrm{K}$ et al. Association of elevated serum lipid levels with retinal hard exudate in diabetic retinopathy. Early Treatment Diabetic Retinopathy Study (ETDRS) Report 22. Arch Ophthalmol 1996; 114(9): 1079-1084.

29 Cusick M, Chew EY, Chan CC, Kruth HS, Murphy RP, Ferris III FL. Histopathology and regression of retinal hard exudates in diabetic retinopathy after reduction of elevated serum lipid levels. Ophthalmology 2003; 110(11): 2126-2133.

30 Karamanos B, Porta M, Songini M, Metelko Z, Kerenyi Z, Tamas $G$ et al. Different risk factors of microangiopathy in patients with type I diabetes mellitus of short versus long duration. The EURODIAB IDDM Complications Study. Diabetologia 2000; 43(3): 348-355.

31 DeNavas-Walt C, Proctor BD, Smith J. Income, Poverty, and Health Insurance Coverage in the United States: 2006. US Census Bureau: Washington, 2007. p 59.

32 Zoega GM, Gunnarsdottir T, Bjornsdottir S, Hreietharsson $\mathrm{AB}$, Viggosson G, Stefansson E. Screening compliance and visual outcome in diabetes. Acta Ophthalmol Scand 2005; 83(6): 687-690.

33 Gray RH, Blades C, Jobson C. Screening clinic nonattendance and the risk of sight threatening retinopathy. Eur J Ophthalmol 2009; 19(3): 510.

34 Scanlon PH, Carter SC, Foy C, Husband RF, Abbas J, Bachmann MO. Diabetic retinopathy and socioeconomic deprivation in Gloucestershire. J Med Screen 2008; 15(3): 118-121.

35 Gale EA. How to survive diabetes. Diabetologia 2009; 52: 559-567.

36 Szydlo D, van Wattum PJ, Woolston J. Psychological aspects of diabetes mellitus. Child Adolesc Psychiatr Clin N Am 2003; 12(3): 439-458, vi.

37 Rose M, Fliege H, Hildebrandt M, Schirop T, Klapp BF. The network of psychological variables in patients with diabetes and their importance for quality of life and metabolic control. Diabetes Care 2002; 25(1): 35-42.

38 Weinger K, Jacobson AM. Psychosocial and quality of life correlates of glycemic control during intensive treatment of type 1 diabetes. Patient Educ Couns 2001; 42(2): 123-131.
39 Schram M, Baan C, Pouwer F. Depression and quality of life in patients with diabetes: a systematic review from the european depression in diabetes (EDID) research consortium. Curr Diabetes Rev 2009; 5(2): 112-119.

40 Gastaldi G, Ruiz J, Giusti V. Patient with type 2 diabetes: don't forget eating disorders!. Rev Med Suisse 2009; 5(196): 667-670.

41 Goebel-Fabbri AE, Fikkan J, Connell A, Vangsness L, Anderson BJ. Identification and treatment of eating disorders in women with type 1 diabetes mellitus. Treat Endocrinol 2002; 1(3): 155-162.

42 Goebel-Fabbri AE. Disturbed eating behaviors and eating disorders in type 1 diabetes: clinical significance and treatment recommendations. Curr Diab Rep 2009; 9(2): 133-139.

43 Reddy VM, Zamora RL, Olk RJ. Quantitation of retinal ablation in proliferative diabetic retinopathy. $A m \mathrm{~J}$ Ophthalmol 1995; 119(6): 760-766.

44 Bailey CC, Sparrow JM, Grey RH, Cheng H. The National Diabetic Retinopathy Laser Treatment Audit. III. Clinical outcomes. Eye 1999; 13(Part 2): 151-159.

45 Bailey CC, Sparrow JM, Grey RH, Cheng H. The National Diabetic Retinopathy Laser Treatment Audit. II.

Proliferative retinopathy. Eye 1998; 12(Part 1): 77-84.

46 Nahberger D, Meyer-Schwickerath R, Saygili O, Gronemeyer U. Development of neovascularization of the optic papilla, retina and iris. Dependence on site and extent of retinal ischemia. Ophthalmologe 2000; 97(6): 422-428.

47 Hayakawa K. Outcome of vitrectomy for proliferative diabetic retinopathy with iris or angle rubeosis. Japanese J Clin Ophthalmol 2006; 60(5): 797-800.

48 Nabili S, Kirkness CM. Trans-scleral diode laser cyclophotocoagulation in the treatment of diabetic neovascular glaucoma. Eye 2004; 18(4): 352-356.

49 Oshima Y, Sakaguchi H, Gomi F, Tano Y. Regression of iris neovascularization after intravitreal injection of bevacizumab in patients with proliferative diabetic retinopathy. Am J Ophthalmol 2006; 142(1): 155-158.

50 Jiang Y, Liang X, Li X, Tao Y, Wang K. Analysis of the clinical efficacy of intravitreal bevacizumab in the treatment of iris neovascularization caused by proliferative diabetic retinopathy. Acta Ophthalmol 2008; 27(7): 7236-7240. 